\title{
Role of ribosome release in the basal level of expression of the Escherichia coli gene phe $A$
}

\author{
Narasaiah Gavini*1 and LaKshmidevi Pulakat ${ }^{2}$ \\ ${ }^{1}$ Department of Molecular Biology and Biochemistry, School of Biological Sciences, University of California at Irvine, Irvine, \\ California 92717, USA \\ ${ }^{2}$ Russell Grimwade School of Biochemistry, University of Melbourne, Parkville, Victoria 3052, Australia
}

(Received 31 July 1990; revised 21 September 1990; accepted 19 November 1990)

\begin{abstract}
In Escherichia coli, the expression of the phenylalanine biosynthetic operon phe $A$ is regulated by an attenuation mechanism. In the presence of excess phenylalanine, gene expression was decreased to $10 \%$ of the fully deattenuated level. To understand the factors that determine the basal level of phe $A$ expression, we examined the role of ribosome release from the leader peptide stop codon UGA. The transcriptional readthrough from the phe $A$ attenuator decreased by over 2 -fold in the presence of the defective release factor 2 . However, a release factor 1 (UAG and UAA specific) mutation did not influence the basal level of phe $A$ expression. These results support the proposal that the release of translating ribosomes from the leader peptide stop codon in stem 2 of the phe attenuator plays a crucial role in determining the basal level of expression of this gene.
\end{abstract}

\section{Introduction}

The amino acid phenylalanine is synthesized in three steps from chorismate, the final intermediate in the common pathway of aromatic biosynthesis. In Escherichia coli, the first two of these steps are catalysed by the bifunctional enzyme chorismate mutase/prephenate dehydratase (EC 5.4.99.5/4.2.1.51), which is encoded by the gene phe $A$ (Pittard, 1987). Nucleotide sequence analysis of the phe $A$ leader region suggests that the phe $A$ gene is regulated by an attenuation mechanism (Zurawski et al., 1978). The leader region of pheA has a short open reading frame (phe $L$ ) capable of encoding a fifteen amino acid polypeptide, which is preceded by a potential ribosome binding sequence AGGA (Fig. 1a). The pheA leader transcript is 145 nucleotides long and has the potential to form several mutually exclusive secondary structures (Kolter \& Yanofsky, 1982; Landick \& Yanofsky, 1987; Yanofsky, 1988). These secondary structures include a stem and loop designated $3: 4$, which has the usual features of a transcription terminator (Fig. 1; Adhya \& Gottesman, 1978; Yager \& Von Hippel, 1987). It was demonstrated that the transcription terminates at the string of thymines immediately $3^{\prime}$ to this stem and loop (Hudson \& Davidson, 1984).

Previous studies have shown that the expression of the phe $A$ gene is decreased by about $90 \%$ when the cells are grown in the presence of phenylalanine (Im \& Pittard, 1971; Gowrishankar \& Pittard, 1982b; Gavini, 1988). This indicates that approximately $10 \%$ of the RNA polymerase molecules read through the attenuator terminator to ensure the basal level expression of pheA. Therefore, it is reasonable to assume that, under these physiological conditions, the formation of the antiterminator structure is favoured against the formation of the terminator about $10 \%$ of the time. By analogy with other well-characterized attenuator systems, it is the rate of movement of the leader-peptide-translating ribosome, in collaboration with the strength of the mutually exclusive secondary structures, that set up the basal level expression (Yanofsky, 1981; Yanofsky et al., 1984; Yanofsky, 1988).

Studies on the mechanism of translational termination have shown that protein release factors play a crucial role in the release of ribosomes from mRNA at stop codons (Caskey, 1980; Hershey, 1987). In E. coli, the release factor 1 (RF1) recognizes the stop codons UAA and $\mathrm{UAG}$, and release factor 2 (RF2) recognizes the stop codons UAA and UGA (Craigen et al., 1985; Craigen \& Caskey, 1986; Ryden et al., 1986; Hershey, 1987; Grunberg-Manago, 1987). Ryden \& Isaksson (1984) have isolated a temperature-sensitive mutation in release factor $1(\operatorname{prf} A[\mathrm{Ts}])$, and have shown that introduction of this mutation decreases the ribosome release from 
mRNA at UAA and UAG stop codons. However, this mutation did not seem to affect the ribosome release from the stop codon UGA. On the other hand, the ribosome release from UGA and from UAA stop codons was affected by mutations in $\operatorname{pr} B$, which encodes release factor 2 (Kawakami et al., 1988).

Recently, Yanofsky and colleagues have shown that ribosome release from the stop codon located in stem 2 has a significant role in determining the basal level expression of the trp operon (Roesser \& Yanofsky, 1988; Rosser et al., 1989). Since the translation termination codon of the phe $A$ leader peptide is located in stem 2(Fig. 1), by analogy with the trp attenuator, ribosome release from this stop codon may play a significant role in determining the basal level expression of the phe $A$ gene. In this report, by taking advantage of the existing $\operatorname{prf} A$ and $p r f B$ mutations, we have examined the role of ribosome release in determining the basal level expression of phe $A$.

\section{Methods}

Strains and growth conditions. The bacterial strains and phages used in this study are listed in Table 1. E. coli strains were grown in Luria broth, LB agar or minimal media supplemented with $0.2 \%$ glucose and appropriate growth factors (Maniatis et al. 1982). $\mathrm{Lac}^{+}$phenotype was identified by growing cells on LB agar plates containing $0.05 \% 5$ bromo-4-chloro-3-indolyl- $\beta$-D-galactopyranoside (X-gal) or MacConkey-lactose agar plates. Tetracycline was used at a concentration of $15 \mu \mathrm{g} \mathrm{ml}^{-1}$ when required. E. coli strains were routinely grown at $37^{\circ} \mathrm{C}$. The temperature sensitive $E$. coli strain UL213 and its derivatives were grown at $30{ }^{\circ} \mathrm{C}$. When used to propagate bacteriophage $\mathrm{P} 1$, cells were grown in $\mathrm{Z}$ broth (LB supplemented with $5 \mathrm{mM}-\mathrm{CaCl}_{2}$ ) and to propagate $\lambda$ phage, cells were grown in $Z$ broth supplemented with $0.2 \%$ maltose.

Construction of E. coli NG200. The $\lambda$ pphe A-lac carries transcriptional fusion in which the lac $Z$ expression is under the control of phe $A$ promoter-attenuator (Gowrishankar \& Pittard, 1982a). Hence all the constraints that apply to the expression of phe $A$ can be easily monitored by measuring the $\beta$-galactosidase activity. This $\lambda$ phage has been integrated into the chromosome of a variety of $E$. coli strains used in the study of the regulation of pheA expression (Gowrishankar \& Pittard, $1982 b$; Gavini, 1988). To construct $E$. coli strain NG200, the E. coli NG3118 (thi-l, lacU169) was used to lysogenise with $\lambda$ ppheA-lac. To isolate $\lambda$ lysogens, the recipient strain was grown to exponential phase $\left(\mathrm{OD}_{600}=0.5\right)$ and $0.2 \mathrm{ml}$ cells were mixed with $3 \mathrm{ml}$ soft agar and layered on to Z-agar plates. These plates were incubated at $37^{\circ} \mathrm{C}$ for $2 \mathrm{~h}$. Samples of phage $\left(10 \mu \mathrm{l}\right.$ of $10^{5}$ p.f.u ml $\left.\mathrm{m}^{-1}\right)$ were spotted onto the lawn of recipient cells and the plates were incubated for $16 \mathrm{~h}$ at $30^{\circ} \mathrm{C}$. Colonies were isolated from the centres of the turbid plaques and were streaked onto plates which had been prespread with $\lambda$ cIb2. Single colonies were purified and were tested for $\lambda$ lysogeny. Monolysogens were identified as described previously (Simons et al., 1987).

Construction of E. coli NG201. The temperature-sensitive release factor 1 mutation $\operatorname{prf} A(\mathrm{Ts})$ was transfered from $E$. coli strain UL213 to NG200 by P1 transduction to construct NG200:RF1. Since the $\operatorname{prfA}(\mathrm{Ts})$ mutation is linked to the tet ${ }^{r}$ transposon $\mathrm{Tn} 10$, the transfer of this mutation could be easily identified by selecting for tet transductants and testing them for temperature sensitivity at $42^{\circ} \mathrm{C}$. The $\mathrm{Pl}$ transduction was carried out as follows. The recipient strain was grown in $\mathrm{Z}$ broth overnight and after concentrating 10-fold, $0.2 \mathrm{ml}$ cell suspension was mixed with $10^{9}$ p.f.u of $P 1$ lysate. This mixture was added to fresh $Z$ broth to give a final volume of $5 \mathrm{ml}$. After incubation at $30^{\circ} \mathrm{C}$ for $20 \mathrm{~min}$ for adsorption, the unadsorbed phage were removed by centrifugation and the cell pellets were washed three times with $0 \cdot 1 \mathrm{M}$-sodium citrate ( $\mathrm{pH} 5 \cdot 5$ ). Finally, these cell pellets were resuspended in $0.5 \mathrm{ml}$ of $0.1 \mathrm{M}$-sodium citrate (pH 5.5) and appropriate dilutions were plated onto agar plates. The plates were incubated at $37^{\circ} \mathrm{C}$ for $4 \mathrm{~h}$ and soft agar containing $15 \mu \mathrm{g} \mathrm{ml}^{-1}$ of tetracycline was layered onto the plates. The tet ${ }^{r}$ colonies carrying the $\operatorname{prf} A(\mathrm{Ts})$ mutations were selected by testing for their inability to grow at $42{ }^{\circ} \mathrm{C}$.

Construction of E. coli NG203. The E. coli strain NG3118 (thi-l, lac U169) was used as a recipient in the P1 transduction experiment employed to transfer the release factor 2 mutation $p r f B 3$ from the $E$. coli strain YN2980 (Kawakami et al., 1988). The P1 transduction was carried out as described above. The prfB3 mutation is $50 \%$ cotransducible with the transposon $\mathrm{Tn} 10$ carrying the tet marker. Therefore tet $^{r} \mathrm{P} 1$ transductants could be selected for the transfer of prfB3 mutation. Since there is no marker (such as temperature sensitivity) associated with the $\operatorname{prfB} 3$ allele, the transfer of this mutation was tested in a different manner from that of the RFl mutation. It has previously been shown that the presence of release factor 2 mutation decreased the transcriptional readthrough from the trp attenuator 2-fold (Roesser \& Yanofsky, 1988; Roesser et al., 1989). We had constructed a transcriptional fusion of the promoter attenuator region of trp and truncated lacZ in the $\lambda R S 88$ (Simons et al., 1987). Ten tet $P 1$ transductants were selected and were lysogenized with the $\lambda$ phage carrying this trp-lacZ fusion. Lysogenization was carried out as described above and monolysogens were selected from each experiment. Comparison of the $\beta$-galactosidase produced from these 10 different monolysogens showed that 4 of them had a twofold decrease in the transcriptional readthrough from the trp attenuator. The original colonies from which these lysogens were derived were selected as containing the RF2 mutations. One of these colonies was selected for further studies and was designated NG202 (Table 1). The E. coli strain NG202 was then used to generate a monolysogen of $\lambda$ pphe A-lac designated NG203 as described above.

\section{Results}

\section{Effect of prfB3 allele on the basal level expression of pheA operon}

The leader peptide of phe $A$ is 15 residues long, and a stop codon UGA is positioned in stem 2 of the attenuator (Fig. 1). It is postulated that a translating ribosome occupies about 12 bases on the mRNA either side of the codon (Gold \& Stormo, 1987). This would prevent stem 2 from base pairing with either stem 1 or stem 3 and would lead to a situation which favours the formation of the transcription terminator; i.e. the $3: 4$ stem-loop of the attenuator. However, if the ribosome is released from the stop codon, stem 2 will be free again and will base pair with either stem 1 or stem 3 depending upon their relative stabilities. Because of this reason, translation of the leader mRNA up to the stop codon, and release of the translating ribosome from the appropriately positioned UGA stop codon in stem 2, become important constraints in determining the basal level expression of this 

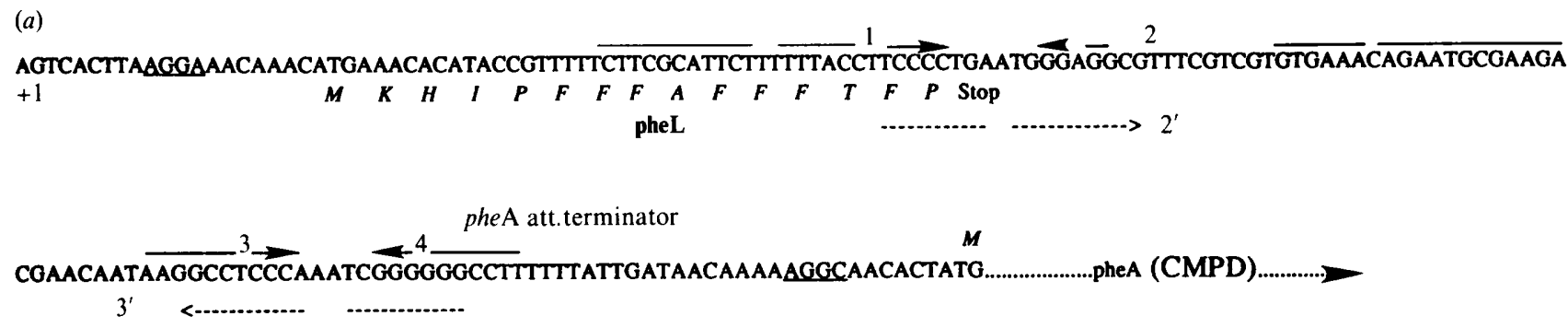

(b)
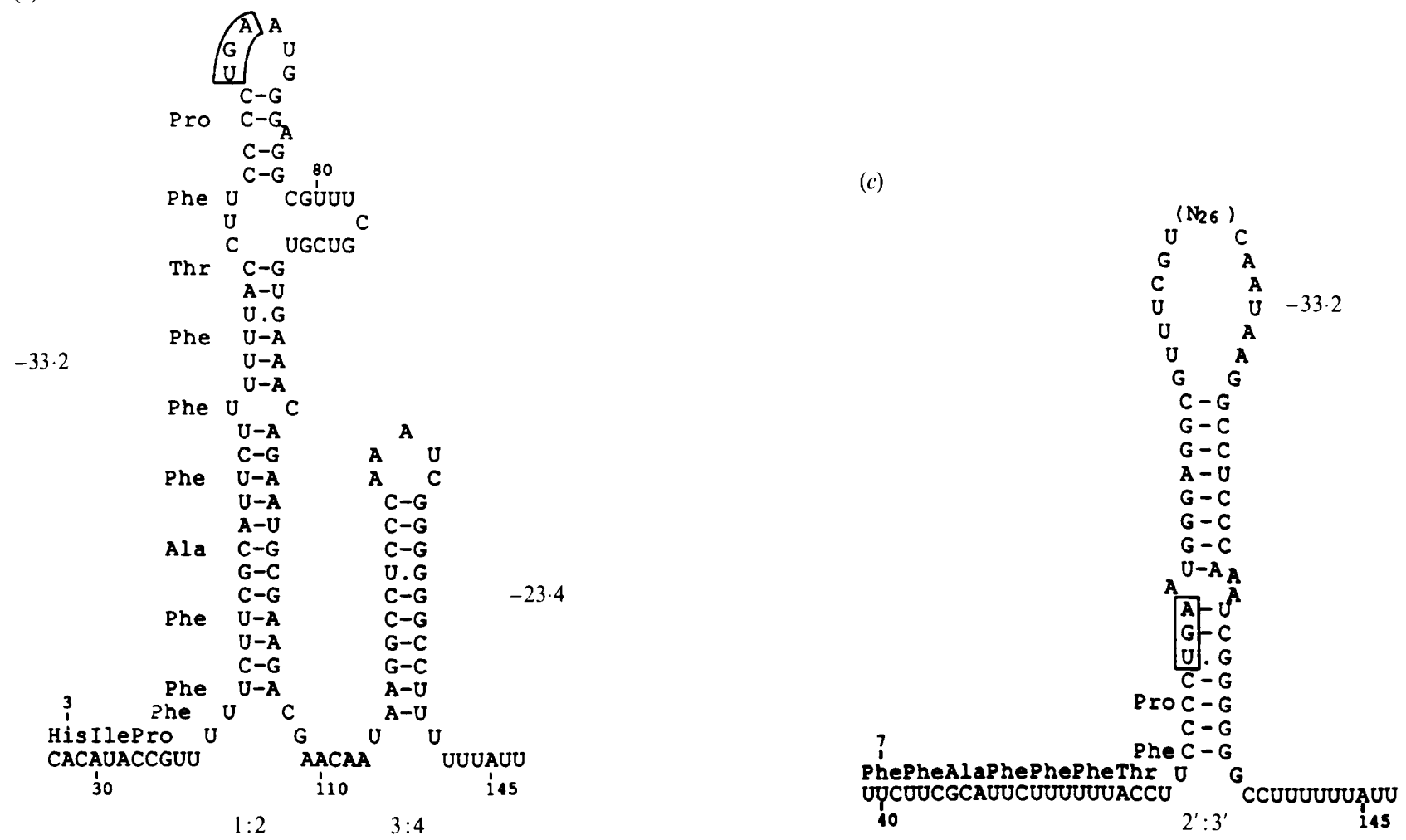

Fig. 1. Predicted alternative secondary structures of the $E$. coli phe $A$ leader transcripts implicated in regulation by transcription attenuation. (a) The DNA corresponding to the leader transcript and translation initiation codon of pheA (Zurawski et al., 1978; Hudson \& Davidson, 1984). The first nucleotide of the transcript is labelled +1 . The nucleotides corresponding to putative ribosome binding sites of phe L and phe $A$ are underlined. The deduced amino acid sequence of the phe leader peptide (pheL) is shown in single letter code. Regions of the sequence which are involved in the formation of predicted alternative secondary structures $1: 2$ and $3: 4$ are shown by overlining with opposing arrows. The nucleotides involved in the formation of the $2: 3$ antiterminator are marked underneath the sequence as $2^{\prime}$ and $3^{\prime}$. CMPD (chorismate mutase/prephenate dehydratase) represents the coding region of phe A. (b) Predicted $1: 2$ and $3: 4$ structures. The third amino acid in the leader peptide is marked 3, and the stop codon UGA is boxed. The numbering on the nucleotides corresponds to the length of the leader transcript. The predicted strength of secondary structures, calculated as described by Tinoco et al. (1973), are shown. (c) Predicted 2:3 antiterminator structure, labelled as for $b$.

operon. Accordingly, it can be postulated that the release factor 2, which is shown to be needed for efficient ribosome release from UGA and UAA stop codons, is required for the normal basal level expression of the phe $A$ operon. Since pheL has a stop codon UGA, and mutations in $\operatorname{prf} B$ (the gene encoding the release factor 2 ) are known to decrease the ribosome release from the stop codons UGA and UAA, we have examined the effect of the $\operatorname{prf} B 3$ allele on the basal level expression of phe $A$. As described in Methods, the E. coli strain NG202 carrying this mutation was used to lysogenize with the $\lambda$ ppheA-lac phage to generate the strain NG203. The amount of $\beta$ galactosidase produced from this $\lambda$ ppheA-lac in the presence (NG203) and absence (NG200) of the prfB3 allele is given in Table 2. It was observed that the presence of $\operatorname{prfB}$ mutation decreased the amount of 
Table 1. E. coli strains and bacteriophages used in this study

\begin{tabular}{|c|c|c|}
\hline $\begin{array}{l}\text { Strains } \\
\text { and phages }\end{array}$ & Characteristics & $\begin{array}{l}\text { Source or } \\
\text { reference }\end{array}$ \\
\hline \multicolumn{3}{|l|}{ E. coli } \\
\hline UL213 & 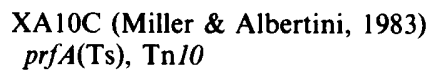 & $\begin{array}{l}\text { (Ryden \& } \\
\text { Isaksson, 1984) }\end{array}$ \\
\hline YN2980 & LS653 (Soll, 1974), prfB3, Tn10 & (Kawakami et al., 1988) \\
\hline NG3118 & thil, lacU169 & N. Gavini (unpublished) \\
\hline NG200 & NG3118, $\lambda \mathrm{p} p h e A-l a c$ & This work \\
\hline NG201 & NG200, Tet ${ }^{\mathrm{r}}, p r f A(\mathrm{Ts})$ & This work \\
\hline NG202 & NG3118, Tetr, prfB3 & This work \\
\hline NG203 & NG202, $\lambda$ pphe $A$-lac & This work \\
\hline NG250 & NG3118, $\lambda$ ptrp-lac & This work \\
\hline NG251 & NG202, $\lambda$ ptrp-lac & This work \\
\hline \multicolumn{3}{|l|}{ Phages } \\
\hline$\lambda$ ppheA-lac & $\mathrm{Lac}^{+}$ & $\begin{array}{l}\text { (Gowrishankar \& } \\
\text { Pittard, 1982a) }\end{array}$ \\
\hline$\lambda \mathrm{ptrp}$-lac & $\mathrm{Lac}^{+}$ & $\begin{array}{l}\text { N. Gavini and L. Pulakat } \\
\text { (unpublished) }\end{array}$ \\
\hline P1 virulent & Transducing phage & Laboratory stock \\
\hline
\end{tabular}

Table 2. $\beta$-galactosidase activity in strains carrying pphe-A-lac with or without release factor mutations

Results are the average of six trials.

\begin{tabular}{lllcc}
\hline \hline $\begin{array}{l}\text { E. coli } \\
\text { strain }\end{array}$ & $\begin{array}{l}\text { Resident } \\
\text { release factor } \\
\text { mutation }\end{array}$ & $\begin{array}{l}\text { Relevant } \\
\text { resident } \\
\text { lac fusion }\end{array}$ & \multicolumn{2}{c}{$\begin{array}{l}\beta \text {-Galactosidase } \\
\text { activity* }\end{array}$} \\
\cline { 4 - 5 } \cline { 3 - 5 } & & $30^{\circ} \mathrm{C}$ & $37^{\circ} \mathrm{C}$ \\
\hline NG200 & None & ppheA-lac & 123 & 125 \\
NG201 & RF1 & ppheA-lac & 125 & 119 \\
NG203 & RF2 & ppheA-lac & NA & 57 \\
NG250 & None & ptrp-lac & NA & 250 \\
NG251 & RF2 & ptrp-lac & NA & 130 \\
\hline \hline
\end{tabular}

* Specific activity of $\beta$-galactosidase is expressed according to Miller (1972).

NA Not applicable (since $\operatorname{pr} f(\mathrm{RF} 2)$ is not associated with a temperature sensitive phenotype).

$\beta$-galactosidase produced from the $\lambda$ pphe $A$-lac by about $55 \%$ indicating that the transcriptional readthrough from the phe $A$ attenuator decreased by over 2 -fold when the defective release factor 2 was present in the cell. To verify the presence of the $\operatorname{prfB} 3$ allele, the effect of this mutation on the expression of $\beta$-galactosidase produced from an $E$. coli strain lysogenized with $\lambda$ ptrp-lac was also tested (as described in Methods) and the results are presented in Table 2. Measuring the transcriptional readthrough from the $t r p$ attenuator in the presence (NG251) and absence (NG250) of prfB mutation was selected as a method to test the presence of $\operatorname{prfB}$ mutation, since the synthesis of trp leader peptide also terminates at a UGA stop codon, and it was shown that the $\operatorname{prf} B$ mutation decreased the basal level expression of the trp operon 2-fold (Roesser \& Yanofsky, 1988; Roesser et al., 1989).

\section{A mutation in prfA does not affect the basal level expression of phe $A$}

To test whether the twofold decrease found in the transcriptional readthrough from the phe $A$ attenuator is specifically due to the presence of release factor 2 mutation, we introduced a $\operatorname{prf} A$ mutation which encodes defective release factor 1 into $E$. coli NG200 as described in Methods. The presence of the temperature sensitive prf $A$ mutation could easily be verified since the $E$. coli strain NG201 carrying this mutation could not grow at $42^{\circ} \mathrm{C}$. At $37^{\circ} \mathrm{C}$, the ribosome release from the UAG codon is decreased when the $\operatorname{prf} A$ mutation is introduced in a strain (Ryden \& Isaksson, 1984; Ryden et al., 1986). The amount of $\beta$-galactosidase produced from the $\lambda$ pphe A-lac in the presence (NG201) and absence (NG200) of the $\operatorname{prf} A$ mutation is given in Table 2. It was observed that the amount of $\beta$-galactosidase activity produced at $30^{\circ} \mathrm{C}$ from $\mathrm{NG} 201$ was similar to the amount produced at $37{ }^{\circ} \mathrm{C}$ from the same strain and also similar to the amount produced from NG200 at both temperatures. These results indicate that the presence of defective release factor 1 does not affect the basal level transcriptional readthrough from the attenuator terminator of phe A. Therefore the 2-fold decrease in the basal level expression of phe $A$ in the presence of the $p r f B$ mutation is specifically due to the decrease in the ribosome release from the phe $L$ stop codon caused by the defective release factor 2 . 


\section{Discussion}

In this study we have examined the role of release of translating ribosomes from the leader peptide stop codon in determining the basal level expression of phe A. It has been shown previously that the $\operatorname{prfB} 3$ mutation, which encodes a defective release factor 2 , decreased the basal level of expression of the trp operon (Roesser \& Yanofsky, 1988; Roesser et al., 1989). The leader transcripts of both $t r p$ and phe operons have UGA translation termination codons. Therefore, using the trp attenuator as a control, we have tested the effect of the $\operatorname{prf} B 3$ allele on the basal level expression of phe A. As shown in Table 2 , the $\beta$-galactosidase activity of the $\lambda$ pphe $A$-lac decreased by over 2 -fold in the prf $B 3$ mutants. However, the $\operatorname{prf} A$ mutation, which encodes a defective release factor 1 , did not affect the $\beta$-galactosidase activity (Table 2). Therefore, a deficiency in the function of release factor 2 specifically decreases the transcriptional readthrough from the attenuator terminator of phe $A$. Since the UGA translation termination codon of phe $L$ is located in stem 2 , the deficiency in the ribosome release would lead to stalling of the translating ribosome on the stop codon for longer than usual and occupying stem 2, preventing it from base-pairing with either stem 1 or stem 3 of the attenuator. Stem 3 will then become free to base-pair with stem 4 and this would result in more frequent transcription termination at the attenuator terminator. It is this situation that dictates the low basal level expression of phe $A$ in a strain carrying the $p r f B$ mutation. Thus, identifying that the defective release factor 2 decreases the transcriptional readthrough from the pheA attenuator points out two significant factors that affect the attenuation regulation of phe A : firstly, that the translating ribosome should translate the leader peptide up to the stop codon and secondly, that the translating ribosome should release from the leader peptide stop codon efficiently to ensure normal basal level expression of the phe A gene.

We thank Professor Charles Yanofsky for helpful discussions and providing us with $E$. coli strains carrying release factor mutations. We are also grateful to Professor James Pittard for providing $\lambda$ ppheA-lac and helpful advice.

\section{References}

Adhya, S., \& Gottesman, M. (1978). Control of transcription termination. Annual Review of Biochemistry 47, 967-996.

CASKeY, C. T. (1980). Peptide chain termination. Trends in Biochemical Sciences 5, 234-237.

Craigen, W. J. \& Caskey, C. T. (1986). Expression of peptide chain release factor 2 requires high efficiency frameshift. Nature, London 322, 273-275.
Craigen, W. J., Cook, R. J., Tate, W. P. \& Caskey, C. T. (1985). Bacterial peptide chain release factors: conserved primary structure and possible frameshift regulation of release factor 2. Proceedings of the National Academy of Sciences of the United States of America 82, 3616-3620.

GAVINI, N. (1988). Investigations on the regulation of the Escherichia coli gene pheA. PhD dissertation, University of Melbourne Victoria, Australia.

GoLD, L. \& STORM, G. (1987). Translational initiation. In Escherichia coli and Salmonella typhimurium: Cellular and Molecular Biology, vol. 2, pp. 1302-1307. Edited by F. Neidhardt, J. L. Ingraham, K. Brooks-Low, B. Magasanik, M. Schaechter, and H. E. Umbarger. American Society for Microbiology: Washington DC.

Gowrishankar, J. \& PitTaRD, J. (1982a). Construction from Mu dl (lac $\mathrm{Ap}^{\mathrm{r}}$ ) lysogens of lambda bacteriophage bearing promoter-lac fusions : isolation of $\lambda$ ppheA-lac. Journal of Bacteriology 150, 11221129.

GowRISHanKar, J. \& PitTARD, J. (1982b). Regulation of phenylalanine biosynthesis in Escherichia coli K-12: control of transcription of the phe A operon. Journal of Bacteriology 150, 1130-1137.

Grunberg-Manago, M. (1987). Regulation of the expression of aminoacyl-tRNA synthetases and translation factors. In Escherichia coli and Salmonella typhimurium: Cellular and Molecular Biology, vol. 2, pp. 1386-1409. Edited by F. Neidhardt, J. L. Ingraham, K. Brooks-Low, B. Magasanik, M. Schaechter, and H. E. Umbarger. American Society for Microbiology: Washington DC.

Hershey, J. W. B. (1987). Protein synthesis. In Escnerichia coli and Salmonella typhimurium: Cellular and Molecular Biology, vol. 1, pp. 613-647. Edited by F. Neidhardt, J. L. Ingraham, K. Brooks-Low, B. Magasanik, M. Schaechter, and H. E. Umbarger. American Society for Microbiology: Washington DC.

Hudson, G. S. \& Davidson, B. E. (1984). Nucleotide sequence and transcription of the phenylalanine and tyrosine operons of Escherichia coli K-12. Journal of Molecular Biology 180, 1023-1051.

IM, S. W. K. \& PITTARD, J. (1971). Phenylalanine biosynthesis in Escherichia coli K-12: mutants derepressed for chorismate mutase Pprephenate dehydratase. Journal of Bacteriology 106, 784-790.

KAWAKAMI, K., INADA, T., \& NakamURA, Y. (1988). Conditionally lethal and recessive UGA-suppressor mutations in the $\operatorname{prf} B$ gene encoding peptide chain release. Journal of Bacteriology 170, 53785381

Kolter, R., \& YANofsky, C. (1982). Attenuation in amino acid biosynthetic operons. Annual Review of Genetics 16, 113-134.

LANDICK, R. \& YANOFSKY, C. (1987). Transcription attenuation. In Escherichia coli and Salmonella typhimurium: Cellular and Molecular Biology, vol. 2, pp. 1453-1472. Edited by F. Neidhardt, J. L. Ingraham, K. Brooks-Low, B. Magasanik, M. Schaechter, and H. E. Umbarger. American Society for Microbiology: Washington DC.

Maniatis, T., Fritsch, E. F., \& Sambrook, J. (1982) Molecular Cloning: A Laboratory Manual. Cold Spring Harbor Laboratory, Cold Spring Harbor, N.Y.

Miller, J. H. (1972) Experiments in Molecular Genetics. Cold Spring Harbor Laboratory, Cold Spring Harbor, N.Y.

Miller, J. H. \& Albertini, A. M. (1983) Effects of surrounding sequence on the suppression of nonsense codons. Journal of Molecular Biology 164, 59-71.

PITTARD, A. J. (1987). Biosynthesis of the aromatic amino acids. In Escherichia coli and Salmonella typhimurium: Cellular and Molecular Biology, vol. 1, pp. 368-394. Edited by F. Neidhardt, J. L. Ingraham, K. Brooks-Low, B. Magasanik, M. Schaechter, and H. E. Umbarger. American Society for Microbiology: Washington Dc.

ROESSER, J. R,. \& YANOFSKY, C. (1988). Ribosome release modulates basal level expression of the trp operon of Escherichia coli. Journal of Biological Chemistry. 263, 14251-14255.

RoESSER, J. R,. NAKAMURA, Y. \& YANOFSKY, C. (1989). Regulation of basal level expression of the tryptophan operon of Escherichia coli. Journal of Biological Chemistry 264, 12284-12288.

Ryden, S. M., \& ISAKSSON, L. A. (1984). A temperature-sensitive mutant of Escherichia coli that shows enhanced misreading of UAG/A and increased efficiency for some tRNA non-sense suppressors. Molecular and General Genetics 193, 38-45. 
Ryden, M., Murphy, J., Martin, R., Isaksson, L., \& Gallant, J. (1986). Mapping and complementation studies of the gene for release factor 1. Journal of Bacterioiogy 168, 1066-1069.

Simons, R. W., Houman, F. \& K LeCKNeR, N. (1987). Improved single and multicopy lac-based cloning vectors for protein and operon fusions. Gene 53, 85-96.

SolL, L. (1974). Mutational alterations of tryptophan-specific transfer RNA that generates translational suppressors of the UAA, UAG, and UGA nonsense codons. Journal of Molecular Biology 86, 233243.

Tinoco JR., I., Borer, P. N., Dengler, B., Levine, M. D., Uhlenbeck, O. C., Crothers, D. M. \& Gralla, J. (1973). Improved estimation of secondary structure in ribonucleic acids. Nature New Biologist 246, 40-41.

YAGER, T. H. \& VON HIPPEL, P. H. (1987). Transcript elongation and termination in Escherichia coli. In Escherichia coli and Salmonella typhimurium: Cellular and Molecular Biology, vol. 2, pp. 1241-1275. Edited by F. Neidhardt, J. L. Ingraham, K. Brooks-Low, B. Magasanik, M. Schaechter, and H. E. Umbarger. American Society for Microbiology: Washington DC.

YANOFSKY, C. (1981). Attenuation in the control of expression of bacterial operons. Nature London 289, 751-758.

YANOFSKY, C. (1988). Transcription attenuation. Journal of Biological Chemistry 263, 609-612

YANOFSKY, C., Kelly, R. L. \& HoRN, V. (1984). Repression is relieved before attenuation in the trp operon of Escherichia coli as tryptophan starvation becomes increasingly severe. Journal of Bacteriology 158. 1018-1024

Zurawski, G., Brown, K., Killingly, D. \& Yanofsky, C. (1978). Nucleotide sequence of the leader region of phenylalanine operon of Escherichia coli. Proceedings of the National Academy of Sciences of the United States of America 75, 4271-4275. 